\title{
Application of Electromagnetic Field in Anaerobic Biodigestion in Batch Reactors
}

Julios César de Souza Matos, ${ }^{*}$ Ladislav Rozenský, ZdeněkVrba, Justin Michael Hansen, Miroslav Hájek, Jan Lípa, Caroline Varella Rodrigues, Fernanda Giffoni Fernandes Luz, Marcus César Avezum Alves de Castro, and Sandra Imaculada Maintinguer

\begin{abstract}
Anaerobic digestion processes with biogas production are widely used for organic waste treatment with an emphasis on energy recovery. Some recent studies have demonstrated the influence of magnetism on microbiological activity. These indicate a possible influence on the efficiency of anaerobic digestion. Thus, technologies that act in anaerobic digestion enhancement can contribute to the improvement of treatment of organic compounds. The present study aimed to verify the influence of a constant electromagnetic field on the anaerobic digestion in anaerobic reactors fed with glucose $(2 \mathrm{~g} / \mathrm{L})$ at $37 \pm 2{ }^{\circ} \mathrm{C}$. In each experiment, reactors were operated with a constant electromagnetic field of 5, 7.5, and $10 \mathrm{mT}$. The inoculum was granular sludge from an anaerobic treatment plant in a non-selective media culture. Biogas production, chemical oxygen demand (COD), and solids removal were measured during the experiment. Results showed differences in methane production of $21.5 \%$ and in COD removal of $15 \%$ in the tests with an electromagnetic field of $7.5 \mathrm{mT}$. These results signs for the viability of the application of a constant magnetic field as a biostimulation agent.
\end{abstract}

Keywords: Fermentation; Electromagnetic force; Biogas; Methane; Biostimulation

Contact information: Instituto de Geociências e Ciências Exatas, Universidade Estadual Paulista; UNESP, Av. 24A, 1515, Rio Claro, São Paulo, Brazil; *Corresponding author: matosj.c.s@gmail.com

\section{INTRODUCTION}

The methane gas present in biogas resulting from the anaerobic biodigestion of organic compounds appears as a promising energy alternative (Hájek et al. 2019; Rozenský et al. 2019). It is easily stored, transported, has a high calorific value and can be obtained from several types of organic matter. Plants to manufacture biogas have been built throughout several countries. However, they have a restriction capacity due to deficiencies of biodigester technology.

Anaerobic digestion is a biochemical process that transforms complex organic matter, in the absence of oxygen, into a gas mixture, mainly methane and carbon dioxide through the syntropic action of various types of anaerobic microorganisms. This process is used for the treatment of waste and, as a renewable source of energy, through anaerobic biodigesters (Lyberatos and Sciadas 1999; Börjesson and Ahlgren 2012; Zhang et al. 2014; Adekunle and Okolie 2015). However, such a process is not economically effective enough (Strachotová et al. 2019). Recently, research has shown an increase in the biological activity by the application of a constant magnetic field and an increase in the production of methane through anaerobic digestion. Zieliński et al. (2014) used neodymium magnets, with a field intensity in the range of 0.16 to $0.39 \mathrm{~T}$ in the treatment of dairy waste. Dębowski et al. (2016) applied 0.6 T via a magnetic ceramic ring in the anaerobic digestion 
of algal biomass. Haritwal et al. (2015) studied the anaerobic digestion of cattle manure under the influence of $0.42 \mathrm{~T}$ using a secondary transformer core.

In addition, studies on the application of a constant magnetic field on the activated sludge digestion demonstrated modifications in the monitored parameters and identified the influence of magnetism on the activity of microbial consortium. The range of positive influence of the constant magnetic field presented in the research for aerobic treatment was between 7 and 490 mT (Jung et al. 1993; Zoung et al. 1993; Jung and Sofer 1997; Yavuz and Çelebi 2000). Electromagnetic fields can influence biological systems both in vitro and in vivo (Herbert et al. 1971). Electromagnetic fields can also influence biological reductive dechlorination for decontamination (Dyntar et al. 2018). However, research is needed in order to explain the influence of electromagnetism and, consequently, to allow for the improvement of organic waste treatment technology with energy recovery.

In this sense, the aim of this work was to analyze the influence of a constant electromagnetic field application on methane generation with no selective culture media in anaerobic batch reactors.

\section{EXPERIMENTAL}

\section{Materials}

The inoculum used was a granular sludge obtained from a full-scale up-flow anaerobic sludge blanket (UASB) reactor treating poultry slaughterhouse waste (Dacar Poultry, Tietê, São Paulo, Brazil). The culture medium for microbial growth was $(\mathrm{g} / \mathrm{L})$ : glucose (10.0), meat extract (5.0), yeast extract (5.0), peptone (5.0), sodium bicarbonate (10.0), monobasic potassium phosphate (0.4), and dipotassium phosphate (0.4).

\section{Methods}

Experimental procedure

This study was performed with duplicate (1-L) anaerobic batch reactors filled with a culture medium $(0.5 \mathrm{~L})$, at $37 \pm 2{ }^{\circ} \mathrm{C}$, during $144 \mathrm{~h}$ of operation. The headspace $(0.6 \mathrm{~L})$ of the reactors was filled with $\mathrm{N}_{2}(99.9 \%)$. The reactors were inoculated with granular sludge (100 g/L). The electromagnetic field was generated by the coil-source power supply that was constructed with copper wire and was $1.1 \mathrm{~mm}$ in diameter with $1.5 \mathrm{~kg}$ of copper. The reagent was made inside the coil. The power supply used was a model D.C. power supply TR-9158 (Guangzhou Yihua Electronic Equipment Co., Ltd., Guangzhou, China). The tests were performed for electromagnetic field strengths of 5, 7.5, and $10 \mathrm{mT}$. The chosen magnetic field range sought to be among the lowest range found in the literature for better application in real scales, since the application of the magnetic field could require expenditure of electrical energy.

The magnetic field inside the reactor was measured with a digital Teslameter (Model Phyve; PHYWE Systeme GmbH \& Co. KG Robert-Bosch-Breite, Göttingen, Germany).

\section{Analytical methods}

The variables studied were the sequence of solids chosen to ascertain the efficiency of the removal of solids by the microbial consortium, and the production of biogas and methane to ascertain the conversion of the organic substrate into gases. 
Total volatile solids (TVS), total solids (TS), total fixed solids (TFS), chemical oxygen demand (COD), and pH tests were performed according to APHA, AWWA, and WEF standards (2005). The sugar conversion analyses were performed according to Dobois et al. (1954) and adapted by Herbert et al. (1971).

The internal pressure of the reactors was measured with a Labitrix differential pressure gauge (model XL28.1; Driesen + Kern GmbH, Hamburg, Germany).

The percentage of methane from the biogas was measured with LANDTEC GEM2000 gas analyzer equipment (LANDTEC North America Inc., Colton, CA, USA), with an accuracy of $3 \%$. The volume of biogas produced inside the reagent bottles was estimated using the Clapeyron equation (Eq. 1),

$$
n=P \times V / \mathrm{R} \times T
$$

where $n$ is the number of biogas molecules produced, $P$ is the pressure inside of the reactor, $V$ is the gas volume or headspace volume $(600 \mathrm{~mL}), R$ is the gas constant $(0.0820574587$ $\left.\mathrm{L} \cdot \mathrm{atm} \cdot \mathrm{K}^{-1} \cdot \mathrm{mol}^{-1}\right)$, and $T$ is the operation temperature $(310.15 \mathrm{~K})$.

The mean values of biogas and methane obtained from the duplicate of the anaerobic batch reactors were adjusted using Statistica ${ }^{\circledR}$ software (Statsoft, Trial Version, Aliso Viejo, CA, USA). The maximum value of methane production was obtained by nonlinear sigmoidal adjustment of the modified Gompertz equation according to Eq. 2,

$$
H=P x \exp \left\{-\exp \left[\frac{R m \cdot e}{P}(\lambda-t)+1\right]\right\}
$$

where $H$ is the accumulated value of biogas or methane (mmol/gTVS), $P$ is the production of biogas or potential methane (mmol/gTVS), $\lambda$ is the time interval of the phase Lag (h), and $T$ is 2,718 incubation time (h).

\section{RESULTS AND DISCUSSION}

It was possible to notice that the reactors submitted to a magnetic field with an intensity of $5 \mathrm{mT}$ presented similar dynamics in relation to the removal of the solids, indicating that the procedures were developed satisfactorily. Nevertheless, the applied intensity did not influence anything in terms of modifying the obtained values (Table 1).

Table 1. Initial and Final Solids

\begin{tabular}{|c|c|c|c|}
\hline Average $(5 \mathrm{mT})$ & TS $(\mathrm{g} / \mathrm{L})$ & TVS $(\mathrm{g} / \mathrm{L})$ & TFS $(\mathrm{g} / \mathrm{L})$ \\
\hline & 39.40 & 27.17 & 12.21 \\
\hline Initial & 39.40 & 27,17 & 12.21 \\
& 25.87 & 16.06 & 19.73 \\
\hline Control reactor & 27.77 & 15.92 & 11.85 \\
\hline \multicolumn{3}{|c|}{ Average $(7.5 \mathrm{mT})$} \\
\hline Initial & 41.04 & 27.27 & 13.77 \\
\hline 144 h of operation & 21.97 & 10.36 & 11.61 \\
\hline Control reactor & 27.35 & 16.18 & 11.16 \\
\hline Average $(10 \mathrm{mT})$ & $\mathrm{ST}(\mathrm{g} / \mathrm{L})$ & $\mathrm{STV}(\mathrm{g} / \mathrm{L})$ & $\mathrm{STF}(\mathrm{g} / \mathrm{L})$ \\
\hline Initial & 40.13 & 27.73 & 12.40 \\
\hline 144 h of operation & 24.94 & 15.50 & 9.44 \\
\hline Control reactor & 27.66 & 17.73 & 9.92 \\
\hline
\end{tabular}


The results of the tests under an electromagnetic field of $7.5 \mathrm{mT}$ showed a reduction in the volatile solids that was higher in the magnetized reactor than in the control reactor. There was a verified increase of volatile solids removal of $21 \%$ for the average of the magnetized reactors in relation to the average of the control reactors.

The values of the electromagnetic field tests of $10 \mathrm{mT}$ also indicated a higher percentage of solid removal in the magnetized reactors with $8 \%$ more compared to the control reactor.

The results of $\mathrm{pH}$ (Fig. 1) indicated the effectiveness of $\mathrm{H}+$ by methanogenic activity and reaction with sodium bicarbonate, maintaining the $\mathrm{pH}$ of the reactors within the optimal range, as described by Zhang et al. (2014).

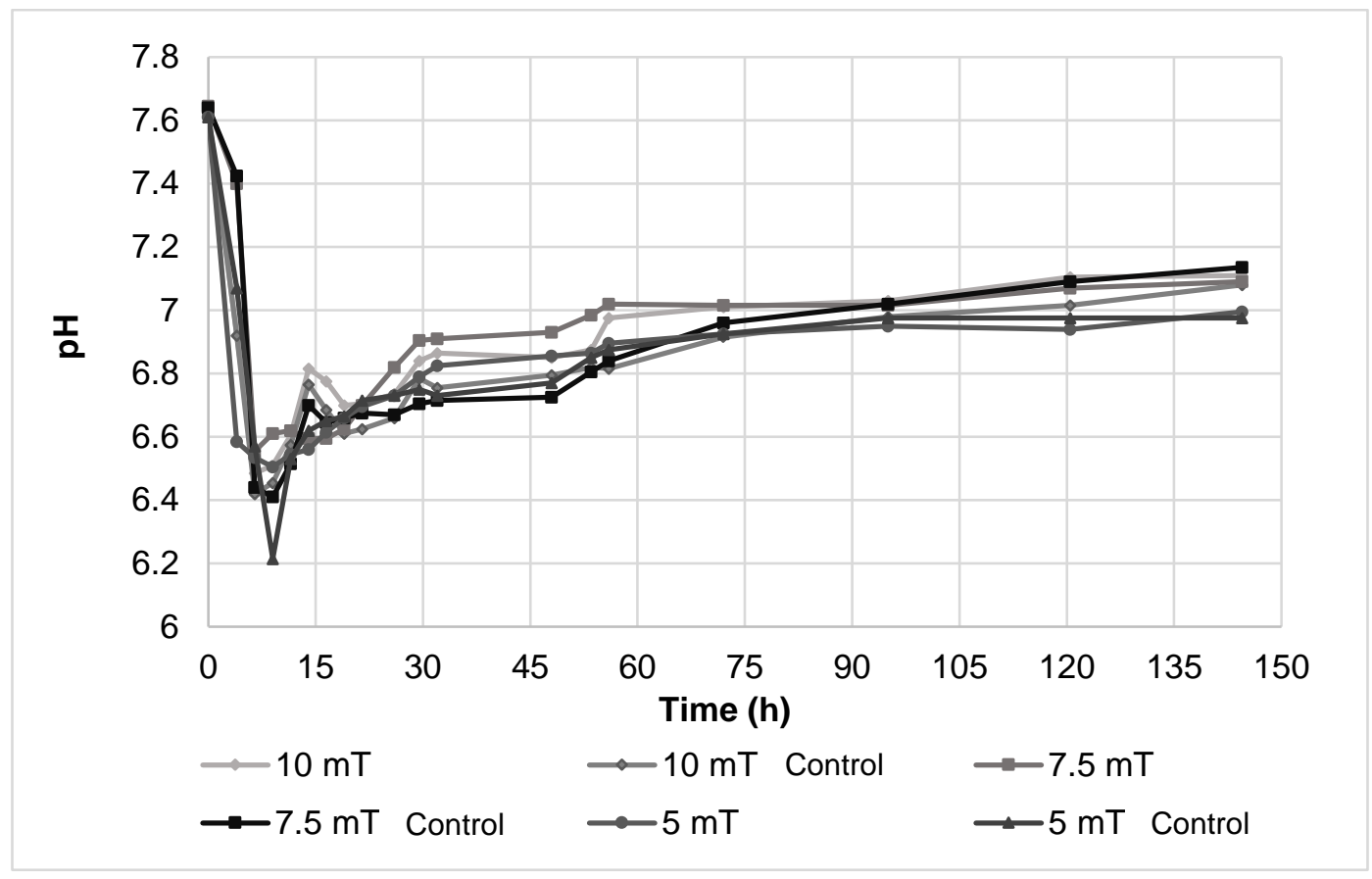

Fig. 1. $\mathrm{pH}$ behaviour during the tests

Effects of $\mathrm{pH}$ change via application of a magnetic field in the water, on the order of +0.62 units, were confirmed by Joshi and Kamat (1966). However, Quickenden et al. (1997) and Gehr et al. (1995) did not observe any change of $\mathrm{pH}$ with magnetic treatment of water. Many studies present changes in the solution $\mathrm{pH}$ under magnetic fields. However, in no study were the authors able to control the $\mathrm{pH}$ of the solution (Parsons et al. 1997).

The COD removal results of the tests with a $5 \mathrm{~m}$ electromagnetic field showed positive values for both reactors (Table 3 ). However, the magnetized reactors had lower values of $0.58 \%$ removal when compared to the control reactors.

Table 3. COD Concentration in Reactors

\begin{tabular}{|c|c|c|c|}
\hline Test & $5 \mathrm{mT}$ & $7.5 \mathrm{mT}$ & $10 \mathrm{mT}$ \\
\hline COD initial $(\mathrm{g} / \mathrm{L})$ & 27.38 & 28.50 & 28.26 \\
\hline Final magnet $(\mathrm{g} / \mathrm{L})$ & 20.97 & 18.80 & 20.48 \\
\hline Removal $(\%)$ & 23.41 & 34.03 & 27.53 \\
\hline Final $(\mathrm{g} / \mathrm{L})$ & 20.81 & 20.08 & 21.04 \\
\hline Removal $(\%)$ & 23.99 & 29.54 & 25.55 \\
\hline
\end{tabular}


The values obtained for the COD consumption of the tests under an electromagnetic field of $7.5 \mathrm{mT}$ showed a $15 \%$ increase in the average removal for the reactors when compared to the mean of the control reactors.

Furthermore, the results obtained for the COD consumption during the tests with reactors under the influence of a $10 \mathrm{mT}$ electromagnetic field presented values that were $7.7 \%$ higher for COD consumption when compared to the average of the control reactors.

Haritwal et al. (2015) found a similar result, a 14\% increase in COD removal in an anaerobic reactor with a magnetic field of $0.42 \mathrm{~T}$, compared to the non-magnetized reactor. Zieliński et al. (2014) also found a 14\% decrease in COD with a magnetized reactor (380 mT). Tomska and Wolny (2008), in a study with a constant magnetic field induction of 40 $\mathrm{mT}$, found no statistically significant difference in the reduction of COD by the aerobic microbial consortium through magnetic biostimulation.

The analysis of sugar consumption revealed that all glucose present in the medium was converted into new compounds by the microbial consortium, metabolized during the first $6.5 \mathrm{~h}$ of operation (Table 4).

Table 4. Glucose Concentration

\begin{tabular}{|c|c|c|c|c|}
\hline & & Initial $(\mathrm{g} / \mathrm{L})$ & $4 \mathrm{~h}(\mathrm{~g} / \mathrm{L})$ & $6.5 \mathrm{~h}(\mathrm{~g} / \mathrm{L})$ \\
\hline \multirow{2}{*}{$5 \mathrm{mT}$} & Magnetized & 9.63 & 1.69 & 0.34 \\
\cline { 2 - 5 } & Control & 9.63 & 1.25 & 0.29 \\
\hline \multirow{2}{*}{7.5} & Magnetized & 9.55 & 2.23 & 0.34 \\
\cline { 2 - 5 } & Control & 9.55 & 2.16 & 0.16 \\
\hline \multirow{2}{*}{$10 \mathrm{mT}$} & Magnetized & 9.51 & 1.58 & 0.07 \\
\cline { 2 - 5 } & Control & 9.51 & 2.33 & 0.26 \\
\hline
\end{tabular}

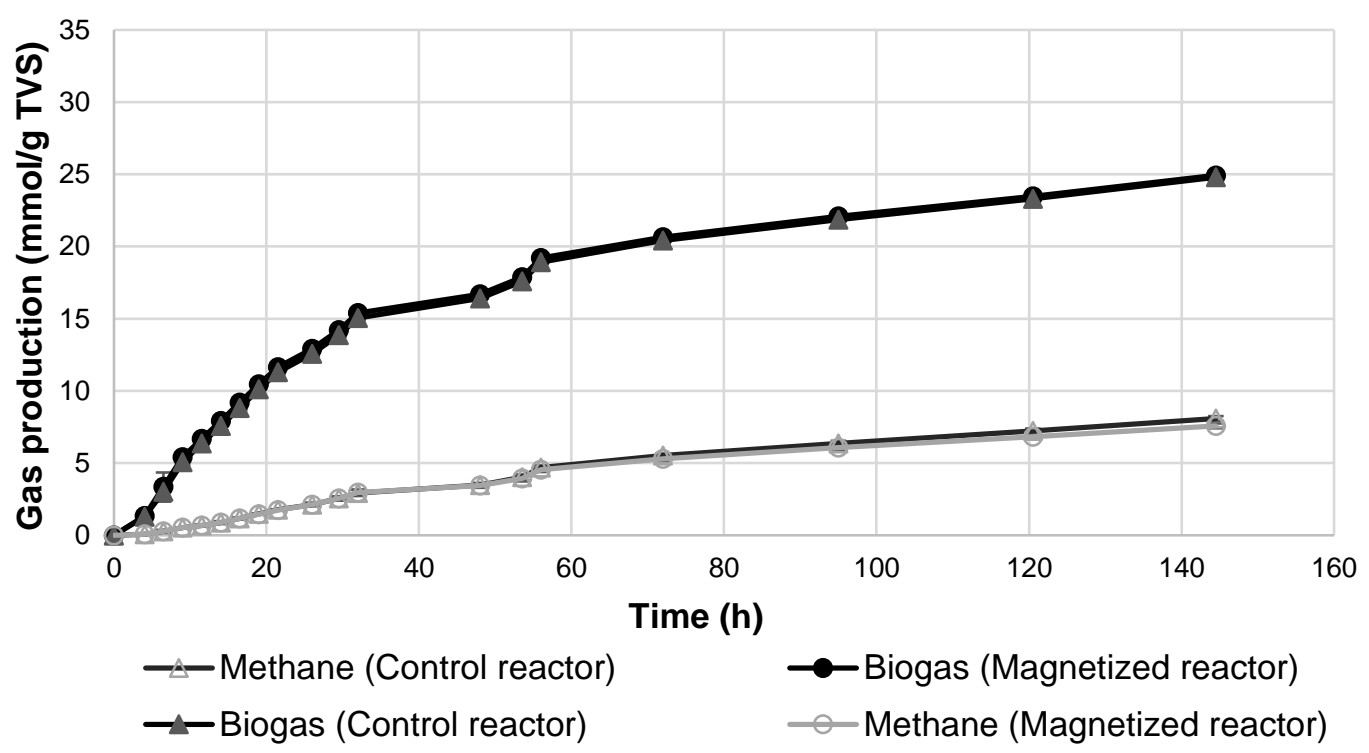

Fig. 2. Estimated accumulated biogas and methane production and average of the two tests in $144 \mathrm{~h}$ of operation under an electromagnetic field of $5 \mathrm{mT}$

Anaerobic biodegradation of simple substrates, such as glucose, are metabolized in acetate, carbon dioxide, and gas-hydrogen or methane gas. In the early stages of anaerobic 
digestion, a degradation of glucose is completed within the first $50 \mathrm{~h}$ of the reaction (Gajaraj et al. 2017). The tests performed with the application of a constant-magnetic field of $5 \mathrm{mT}$ were also not favoured under afield strength with $5 \mathrm{mT}$ (Fig. 2).

The experiments with $7.5 \mathrm{mT}$ showed similar biogas production. However, there was an increase in the methane gas production inside the magnetized reactors compared to that of the control reactors (Fig. 3).

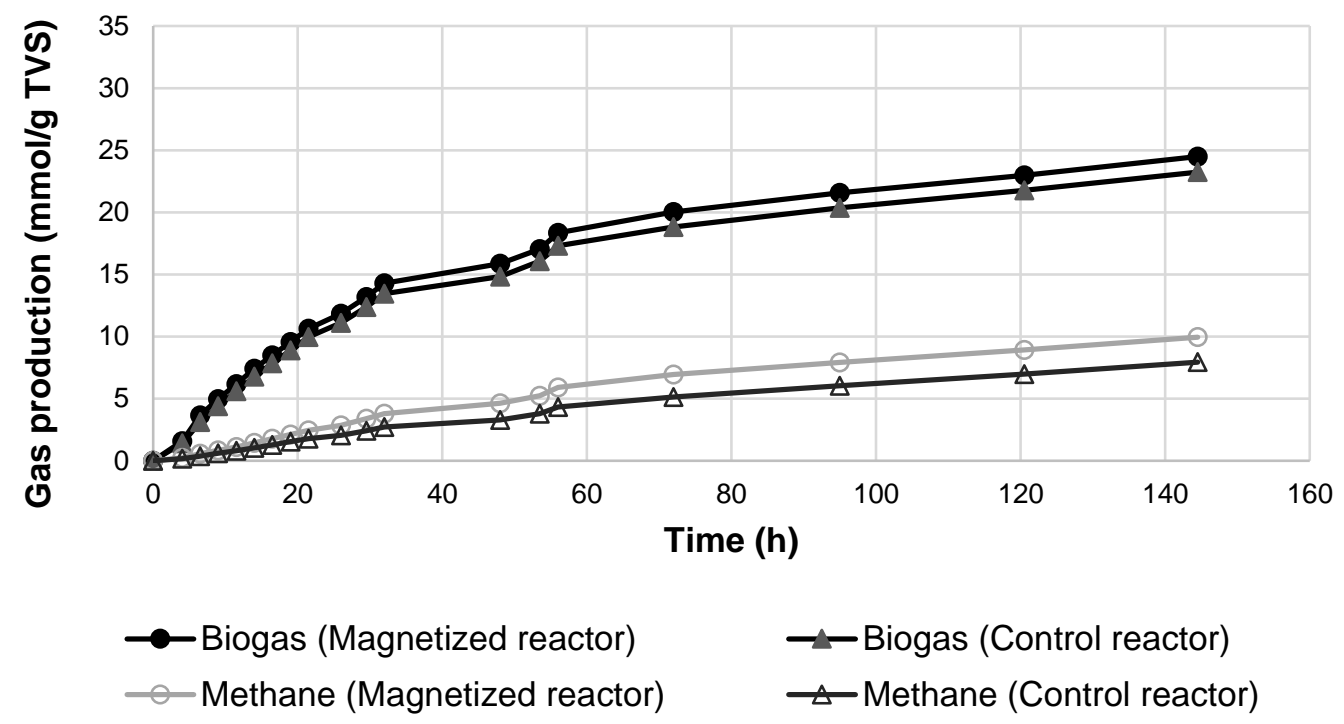

Fig. 3. Estimated accumulated production of biogas and methane and average of the two tests with crude granular mud in $144 \mathrm{~h}$ of operation under an electromagnetic field of $7.5 \mathrm{mT}$

During the experiments with a $10 \mathrm{mT}$ electromagnetic field, the production of biogas was similar in the results. The difference occurred in the production of accumulated methane (Fig. 4).
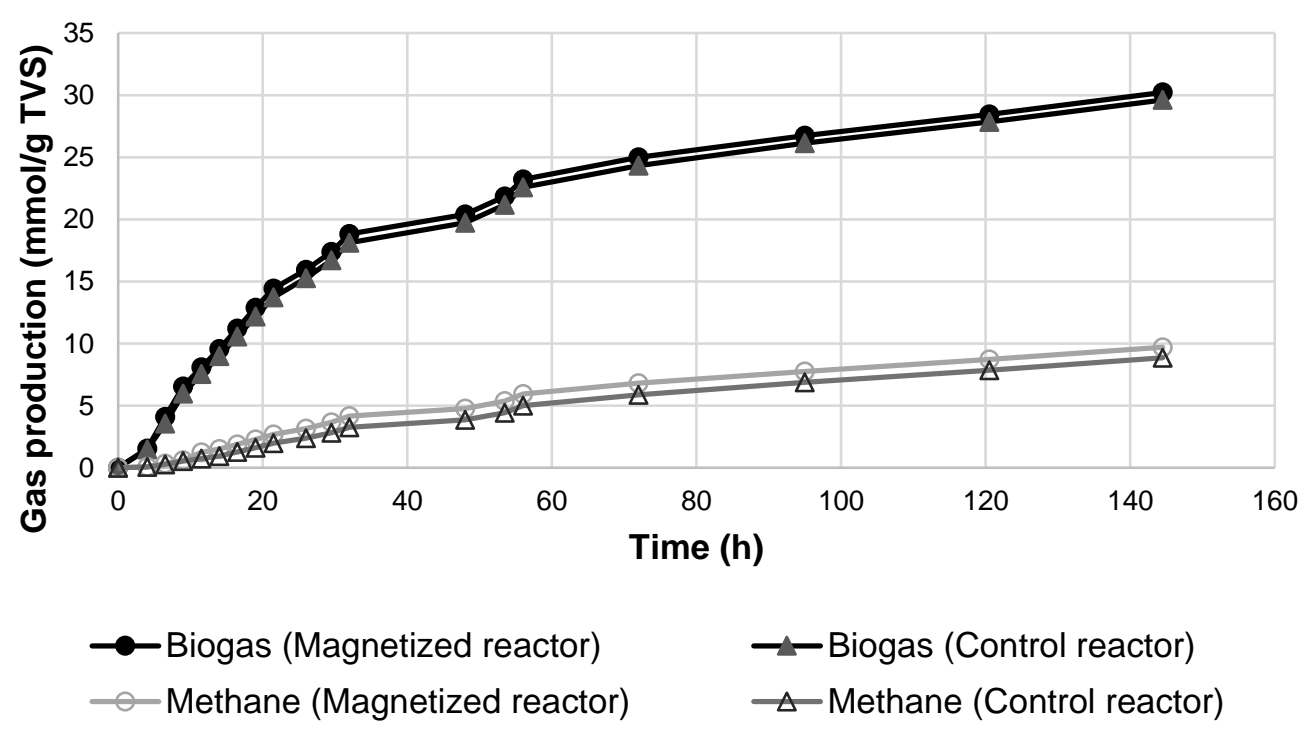

$$
\begin{aligned}
& - \text { Biogas (Control reactor) } \\
& \triangle \text { Methane (Control reactor) }
\end{aligned}
$$

Fig. 4. Estimated accumulated biogas and methane production and average of the two tests with gross granulate in 144 operating $\mathrm{h}$ and a $10 \mathrm{mT}$ electromagnetic field 
The final values obtained from the reference production of methane gas and biogas with the application of the Gompertz model are presented in Tables 5 and 6.

Table 5. Results Obtained Through the Gompertz Model for Biogas Production

\begin{tabular}{|c|c|c|c|c|c|c|}
\hline Biogas & $\begin{array}{c}5 \mathrm{mT} \\
\text { Magnetized }\end{array}$ & $\begin{array}{c}5 \mathrm{mT} \\
\text { Control }\end{array}$ & $\begin{array}{c}7.5 \mathrm{mT} \\
\text { Magnetized }\end{array}$ & $\begin{array}{l}7.5 \mathrm{mT} \\
\text { Control }\end{array}$ & $\begin{array}{c}10 \mathrm{mT} \\
\text { Magnetized }\end{array}$ & $\begin{array}{c}10 \mathrm{mT} \\
\text { Control }\end{array}$ \\
\hline$P(\mathrm{mmol} / \mathrm{gTVS})$ & 22.64 & 22.53 & 22.61 & 21.41 & 27.27 & 26.79 \\
\hline$R m(\mathrm{mmol} / \mathrm{g} \cdot \mathrm{TVS}) / \mathrm{h}$ & 0.44 & 0.43 & 0.38 & 0.36 & 0.55 & 0.53 \\
\hline$\lambda(\mathrm{h})$ & ---- & ----- & ---- & ---- & ---- & ---- \\
\hline$R$ & 0.98 & 0.99 & 0.99 & 0.99 & 0.98 & 0.99 \\
\hline
\end{tabular}

$P=$ Cumulative maximum production; $R m=$ Production rate; $\lambda=$ Time to start production; $R=$ confidence interval

Biogas production began at the beginning of the experiment; accumulated final values and biogas production rates were similar for the three applied magnetic fields.

Table 6. Results Obtained Through the Gompertz Model for Methane Gas Production

\begin{tabular}{|c|c|c|c|c|c|c|}
\hline Methanol & $\begin{array}{c}\mathbf{5 m T} \\
\text { Magnetized }\end{array}$ & $\begin{array}{c}\mathbf{5} \mathbf{~ m T} \\
\text { Control }\end{array}$ & $\begin{array}{c}\mathbf{7 . 5} \mathbf{~ m T} \\
\text { Magnetized }\end{array}$ & $\begin{array}{c}\mathbf{7 . 5} \mathbf{~ m T} \\
\text { Control }\end{array}$ & $\begin{array}{c}\mathbf{1 0} \mathbf{~ m T} \\
\text { Magnetized }\end{array}$ & $\begin{array}{c}\mathbf{1 0} \mathbf{~ m T} \\
\text { Control }\end{array}$ \\
\hline$P(\mathrm{mmol} / \mathrm{gTVS})$ & 7.39 & 7.99 & 9.77 & 8.04 & 9.24 & 8.69 \\
\hline$R m(\mathrm{mmol} / \mathrm{g} . \mathrm{TVS}) / \mathrm{h}$ & 0.09 & 0.09 & 0.11 & 0.08 & 0.11 & 0.09 \\
\hline$\lambda(\mathrm{h})$ & 4.38 & 5.00 & 2.21 & 2.90 & 1.75 & 4.60 \\
\hline$R$ & 0.99 & 0.99 & 0.99 & 0.99 & 0.99 & 0.99 \\
\hline
\end{tabular}

$P=$ Cumulative maximum production; $R m=$ Production rate; $\lambda=$ Time to start production; $R=$ confidence interval

The methanogenic activity obtained the greatest difference when a magnetic field of $7.5 \mathrm{mT}$ was applied to the reactor; the results presented a $21.5 \%$ increase in the accumulated production in relation to the control. In this test, the magnetized reactor started methane production 41.4 min before the control reactor.

The experiment with a $10 \mathrm{mT}$ field showed an accumulated difference that was $6.32 \%$ greater than the magnetized reactors in comparison to the control reactors. In addition, the start of methane production in the magnetized reactors occurred 171 min before the control reactors.

Studies indicate parameter variations in tests with the magnetic field intensity in the range of 7 to $490 \mathrm{mT}$ (Tomska and Wolny 2008).

Furthermore, differences in methane production rates occurred in up to $72 \mathrm{~h}$ of operation. Zieliński et al. (2014) found an increase in the fermentation process through applying a constant magnetic field for the treatment of dairy residue. These authors found changes in COD and sludge sedimentation, but they did not find statistically significant differences in the composition of the biogas with a $4 \%$ increase in production compared to the control while using a constant magnetic field (with an intensity of $431 \mathrm{mT}$ at $0.7 \mathrm{~mm}$ away from the magnet).

However, Haritwal et al. (2015) found a $40 \%$ increase in the methanogenic activity of the reactor submitted to constant magnetic field exposure when compared to the control reactor after six days of reaction. Additionally, they found that the reduction of ammoniacal 
nitrogen was $20 \%$ higher. In another study, promoted by Dębowski et al. (2014), the authors introduced artifacts with neodymium magnets in the zone of hydrolysis and acidogenesis in reactor tanks. In the cited study, powdered milk was used as a substrate, which allowed for a higher biofilm formation and a lower reduction of bacterial biomass losses. The authors of the cited study concluded that there was no statistically significant impact on the increase of investment costs of the entire facility.

The authors' study also showed an increase in biogas production and an increase in methane concentration related to the number of magnetized artifacts used.

\section{CONCLUSIONS}

1. The results of the methane analysis favoured methanogenesis under the constant electromagnetic field of 7.5 with a $21.5 \%$ increase in the accumulated production in relation to the control.

2. The delay phase was shorter when the $10 \mathrm{mT}$ magnetic field was applied. The start of methane production in the magnetized reactors occurred $171 \mathrm{~min}$ before the control reactors.

3. The values obtained for the COD consumption of the tests under an electromagnetic field of $7.5 \mathrm{mT}$ showed a $15 \%$ increase in the average removal for the reactors, when compared to the mean of the control reactors. The highest value of the three fields was tested.

4. However, further studies are needed in order to validate the effect of the magnetic field on anaerobic digestion, as well as its performance in the biological system.

\section{ACKNOWLEDGEMENTS}

The authors are immensely grateful for the financial support of the Coordination for the Improvement of Higher Education Personnel (CAPES), the structural and technical support of the Research Institute for Bioenergy (IPBEN), and the Institute of Geosciences and Environment (IGCE), both of UNESP (Rio Claro, São Paulo).

This paper was supported by the "Advanced Research Supporting the Forestry and Wood-processing Sector's Adaptation to Global Change and the $4^{\text {th }}$ Industrial Revolution (No. CZ.02.1.01/0.0/0.0/16_019/0000803)" grant, and financed by project No. QK1920391, which was financed by the Ministry of Agriculture of the Czech Republic called "Diversification of the Impact of the Bioeconomy on Strategic Documents of the Forestry-Wood Sector as a Basis for State Administration and the Design of Strategic Goals by 2030 ”'.

This paper was additionally supported by the institutional support of Charles University, First Faculty of Medicine, Institute of Humanities in Medicine, Katerinská 32, CZ - 121, Prague 2, Czech Republic, EU. 


\section{REFERENCES CITED}

Adekunle, K. F., and Okolie, J. A. (2015). "A review of biochemical process of anaerobic digestion," Advances in Bioscience and Biotechnology 6(3), 205-212. DOI: 10.4236/abb.2015.63020

American Public Health Association (APHA), AWWA, and WEF (2012). Standard Methods for Examination of Water and Wastewater, $22^{\text {nd }}$ Ed., American Public Health Association, Washington D.C., USA.

Börjesson, M., and Ahlgren, E. O. (2012). "Cost-effective biogas utilisation - A modelling assessment of gas infrastructural options in a regional energy system," Energy 48(1), 212-226. DOI: 10.1016/j.energy.2012.06.058

Dębowski, M., Zieliński, M., Kisielewska, M., and Hajduk, A. (2016). "Effect of constant magnetic field on anaerobic digestion of algal biomass," Environmental Technology 37(13), 1656-1663. DOI: 10.1080/09593330.2015.1126362

Dębowski, M., Zieliński, M., Krzemieniewski, M., and Brudniak, A. (2014). "Effect of magneto-active filling on the effectiveness of methane fermentation of dairy waste waters," International Journal of Green Energy 17(8), 125-137. DOI: 10.1080/15435075.2014.909362

Dyntar, J., Strachotová, D., and Hnátková, T. (2018). "Economical efficiency of biological reductive dechlorination for decontamination of hexachlorocyclohexanecontaminated soil," Waste Forum 2, 132-139.

Gajaraj, S., Huang, Y., Zheng, P., and Hu, Z. (2017). "Methane production improvement and associated methanogenic assemblages in bioelectrochemically assisted anaerobic digestion," Biochemical Engineering Journal 117(Part B), 105-112. DOI: 10.1016/j.bej.2016.11.003

Gehr, R., Zhai, Z. A., Finch, J. A., and Rao, S. R. (1995). "Reduction of soluble mineral concentrations in $\mathrm{CaSO}_{4}$ saturated water using a magnetic field," Water Research 29(3), 933-940. DOI: 10.1016/0043-1354(94)00214-R

Hájek, M., Zimmermannová, J., Helman, K., and Rozenský, L. (2019). “Analysis of carbon tax efficiency in energy industries of selected EU countries," Energy Policy 134, 165-189. DOI: 10.1016/j.enpol.2019.110955

Haritwal, A., Chaudlhary, M., Mohan, D., and Asopa, P. P. (2015). "Study on the improved biogas generation trough magnetic field modified anaerobic digestion," International Journal Engineering Research \& Technology 4(5), 1175-1179.

Herbert, D., Philipps, O. S., and Strang, R. E. (1971). "Carbohydrate analyses," Methods in Enzymology, Vol. 5B, 265-277.

Joshi, K. M., and Kamat, P. V. (1966). "Effects of magnetic field on the physical properties of water," Journal Indian Chemical Society 43, 620-622.

Jung, J., Sanji, B., Godbole, S., and Sofer, S. (1993). "Biodegradation of phenol: A comparative study with and without applying magnetic fields," Journal of Chemical Technology and Biotechnology 56(1), 73-76. DOI: 10.1002/jctb.280560113

Jung, J., and Sofer, S. (1997). "Enhancement of phenol biodegradation by south magnetic field exposure," Journal of Chemical Technology and Biotechnology 70(3), 299-303. DOI: 10.1002 / (sici) 1097-4660 (199711) 70: $3<299$ :: aid-jctb757> 3.0.co; 2-h

Lyberatos, G., and Skiadas, I. V. (1999). "Modelling of anaerobic digestion - A review," Global Nest: The International Journal 1(2), 63-76. 
Parsons, S. A., Wang, S. J., Judd, S. J., and Stephenson, T. (1997). "Magnetic treatment of calcium carbonate scale - Effect of pH control," Water Research 31(2), 339-342. DOI: 10.5151/chemeng-cobeq2014-1691-18023-141875

Quickenden, T. I., Betts, D. M., Cole, B., and Noble, M. (1997). "Effects of magnetic fields on the $\mathrm{pH}$ of water," The Journal of Physical Chemistry 75(18), 2830-2831. DOI: $10.1021 / \mathrm{j} 100687 \mathrm{a} 020$

Rozenský, L., Vrabcová, P., Hájek, M., Veselá, T., and Hukal, P. (2019). "Searching for correlations between $\mathrm{CO}_{2}$ emissions and selected economic parameters," Statistika: Statistics and Economy Journal 99(2), 151-162.

Strachotová, D., Dyntar, J., and Souček, I. (2019). "Risks of investing in alternative diesel biofuel production," Waste Forum 2, 71-83.

Tomska, A., and Wolny, L. (2008). "Enhancement of biological wastewater treatment by magnetic field exposure," Desalination 222(1-3), 368-373. DOI: 10.1007/s10532009-9275-X

Yavuz, H., and Çelebi, S. S. (2000). "Effects of magnetic field on activity of activated sludge in wastewater treatment," Enzyme and Microbial Technology 26(1), 22-27. DOI: 10.1016/S0141-0229(99)00121-0

Zhang, C., Su, H., Baeyens, J., and Tan, T. (2014). "Reviewing the anaerobic digestion of food waste for biogas production," Renewable and Sustainable Energy Reviews 38, 383-392. DOI: 10.1016/j.rser.2014.05.038

Zieliński, M., Debowski, M., Krzemieniewski, M., Dudek, M., and Grala, A. (2014). "Effect of constant magnetic field (CMF) with various values of magnetic induction effectiveness of dairy wastewater treatment under anaerobic conditions," Polish Journal of Environmental Studies 23(1), 255-261.

Article submitted: October 7, 2019; Peer review completed: March 21, 2020; Revised version received and accepted: April 27, 2020; Published: May 13, 2020.

DOI: 10.15376/biores.15.3.4972-4981 